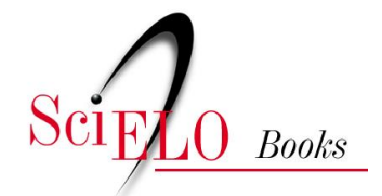

Editora
UEPG

\title{
Políticas sociales en Argentina
}

continuidades y rupturas

Susana Del Valle Cazzaniga

\section{SciELO Books / SciELO Livros / SciELO Libros}

CAZZANIGA, S. D. V. Políticas sociales en Argentina: continuidades y rupturas. In: COSTA, L. C., NOGUEIRA, V. M. R., and SILVA, V. R., orgs. A política social na América do Sul: perspectivas e desafios no século XXI [online]. Ponta Grossa: Editora UEPG, 2013, pp. 157-174. ISBN 978-857798-231-8. Available from: doi: 10.7476/9788577982318.0008. Also available in ePUB from: http://books.scielo.org/id/rfv9p/epub/costa-9788577982318.epub.

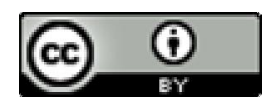

All the contents of this work, except where otherwise noted, is licensed under a Creative Commons Attribution $\underline{4.0 \text { International license. }}$

Todo o conteúdo deste trabalho, exceto quando houver ressalva, é publicado sob a licença Creative Commons Atribição 4.0.

Todo el contenido de esta obra, excepto donde se indique lo contrario, está bajo licencia de la licencia Creative Commons Reconocimento 4.0. 


\section{Políticas sociales en Argentina: continuidades y rupturas}

Susana Del Valle Cazzaniga

\section{Algo está pasando en Latinoamérica, "ipero de qué se trata?"}

El siglo XXI nos sorprendió con una serie de cambios tanto en el orden mundial como regional. Transformaciones políticas, culturales, tecnológicas entre otras, fueron armando una argamasa sobre el aparente "siempre desfalleciendo aunque siempre revitalizándose" sistema capitalista, dando lugar a nuevas, o por lo menos resignificadas, configuraciones sociales. Si bien, en Latinoamérica el escenario es complejo y por momentos confusos, no es posible negar que respiramos un clima de época que no es el mismo que el de la década de 1990 y para el caso argentino, además, bien diferenciado del golpismo cívico militar que caracterizó más de la mitad del siglo XX y también de las inestabilidades económicas de los 80s y 90 s.

Edgardo Mocca (2008), haciendo referencia a este tema, considera que aún con las diferencias entre los países se pueden observar rasgos comunes de este paisaje regional actual, entre los cuales me interesan destacar: el regreso del Estado y de la política a la escena ocupada en décadas anteriores por la lógica del mercado, la emergencia de nuevos actores sociales y nuevas prácticas políticas, la crisis de los partidos políticos tradicionales (cuestión que presenta diferencias sustantivas entre los diversos países) y el desarrollo de una nueva oleada de movilidad y conflictividad social. Estas transformaciones han hecho emerger en los ámbitos intelectuales y académicos una serie de debates que, paulatinamente, se van alejando de la temática recurrente sobre el neoliberalismo y sus implicancias que monopolizara el centro de la escena, para acercarse a "tratar de entender" los acontecimientos que se vienen sucediendo en la Latinoamérica de este nuevo siglo.

Quizás, uno de los más significativos es el que se ha tematizado como "el giro a la izquierda" en tanto logra concitar un verdadero desacuerdo entre los que polemizan ${ }^{1}$. En efecto, encontramos posturas muy diferentes

\footnotetext{
Para comprender el concepto, Arditti (2009) toma a su autor, Ranciere, para quien el desacuerdo es justamente el estructurador de la política y se evidencia en las situaciones en que los interlocutores "nombran" de la misma manera un acontecimiento pero entienden de modo absolutamente diferente el sentido y/o significado de lo que "eso" que se nombra, tiene o quiere decir, dándole visibilidad a diferentes proyectos políticos. (RANCIERE, 1996)
} 
al respecto que en forma general podemos agrupar por lo menos, en tres tendencias: a los que decididamente sostienen que la mayoría de los países latinoamericanos entran en esta categoría y que esta vía logrará poner de pie a la región sesgando la construcción de las sociedades a un socialismo de nuevo cuño; los que argumentan que "este giro" no es hacia la izquierda, sino la aplicación de políticas que, si bien, no pueden ser consideradas como las neoliberales clásicas de los 90, sólo obedecen a las necesidades de la reproducción del capitalismo luego de las fallidas políticas dictadas por el Consenso de Washington y una tercera posición, que se encuentra en aquéllos que, también aseguran el ingreso de la región en las rutas de las izquierdas, pero que fieles a su ortodoxia de derecha, alertan que esto sólo llevará al caos económico, político y lógicamente con derivas funestas para la sociedad. Frente a polémicas con argumentos tan disímiles que demuestran a las claras las diferencias de interpretación, podemos tener una primera constatación: la política ha vuelto al ruedo en forma desembozada, estamos discutiendo proyectos políticos y en la grilla intelectual se produce con horizonte de futuro, rompiéndose el cerco de la pura coyuntura. Si se me concede acuerdo sobre esto último, considero que "algo interesante" está emergiendo.

Coincido con algunos autores, particularmente con el mexicano Benjamín Arditi, en que se hace necesario otorgar ciertos sentidos a la noción de izquierda recuperando el moldeado histórico que la misma ha vivido en Latinoamérica, pero a la luz de la actualidad y singularizando los casos para tratar de identificar qué aspectos se mantienen, cuáles se resignifican; así, según este autor, se podrá comprender si ciertas políticas hacen "diferencia" o son simples señuelos para aplacar seguidores. Por otra parte, alerta que para leer estos giros no sólo debe tenerse en cuenta las tendencias de los gobiernos, sino también, la acción colectiva que logra imponer agendas o el comportamiento de la sociedad civil en torno a problemáticas que hasta el momento no suscitaran movilizaciones. Para Arditi, el escenario que se abre en la región puede ser caracterizado como post liberal, entendiendo que el prefijo post " [...] no anuncia el fin de la política liberal y su reemplazo por otra cosa, pero es evidente que el 'post' también se remite a algo que no puede ser contenido dentro de la forma liberal [...]" (ARDITI, 2009, p.241). En coincidencia con esta interpretación, concluye en que nos encontramos frente a una hibridización política.

En este marco de "hibridización" política los proyectos sociales se van construyendo en la región en que encontramos desde los principios del "buen vivir”, el sumak kawsay (DÁVALOS, 2011) más propios de los países donde la población indígena es un sujeto político activo como Bolivia y Ecuador, hasta el mantenimiento de acuerdos con el imperio que refuerzan la dependencia, 
con organizaciones sociales más débiles como para revertirlos o la toma de fuertes decisiones de renacionalización de la propiedad privatizada de núcleos económicos sustantivos (PETRAS, 2007). Y es también, en estas realidades complejas en que se erigen los dispositivos de las políticas sociales.

\section{Sobre las políticas sociales: cuestiones conceptuales e históricas}

En principio, podemos decir que las políticas sociales aparecen de la mano de circunstancias particulares en la fase monopolista del capitalismo, donde el Estado se hace cargo de dar respuesta a la cuestión social; de esta manera, son también producto de largas luchas obreras y sociales. Desde esta perspectiva, ellas expresan los modos, manifestaciones y derivaciones de los conflictos de clase, la institucionalidad social que se configura para abordarlos, las características que asume el régimen de acumulación capitalista en cada país y las particularidades del estado, cuestiones todas que hacen que las políticas sociales presenten variaciones históricas. En esa línea Nora Britos expresa que

[...] constituyen una constelación institucional cuyo examen nos permite [...] identificar los conflictos sociales y políticos a cuyo encauzamiento, dirección y modificación se han dirigido históricamente estas intervenciones estatales. Implícita o explícitamente se basan y establecen criterios de justicia y en particular producen efectos sobre la integración social [...]. (BRITOS, 2004, p.2).

Recuperando la perspectiva histórica, y en términos generales las políticas sociales toman encarnadura en lo que se dio en llamar Estado de Bienestar, y si bien es imposible considerar un modelo único de éste, en tanto han existido variantes significativas (ESPING ANDERSEN, 1993) ${ }^{2}$ hay que recordar que su expansión y mayor grado de concretud se encuentra en los países europeos. En efecto, la salida de la segunda guerra mundial exige la reconstrucción de las sociedades reconociendo la necesidad de intervención estatal, que a la par que daba respuestas a las reivindicaciones sociales reconociendo derechos, intentaba disminuir desigualdades, actuando a la vez como escudo protector de los avances socialistas o de las impugnaciones al orden establecido. La investigación comparativa sobre los Estados de Bienestar realizada por Esping-Andersen pone al descubierto aspectos bien interesantes

2 Esping Andersen expresa que no todos los Estados de bienestar son del mismo tipo. “...En realidad, el estudio que aquí se presenta identifica tres tipos de regímenes altamente diferenciados, cada uno de ellos organizado con su propia y diferente lógica de organización, estratificación e integración social. Los orígenes de cada uno se deben a distintas fuerzas históricas y siguen unas trayectorias de desarrollo cualitativamente diferente". (ESPING-ANDERSEN, 1993, p.19). 
- que sin desconocer las coordenadas tiempo/espacio de este estudio, antes bien, teniéndolas en cuenta para no hacer extrapolaciones inconducentes nos dan algunas pistas para poder introducirnos a la cuestión de las políticas sociales en estos lares, particularmente, en Argentina.

En efecto, me interesa resaltar de esta producción en particular dos temas: el que refiere a los distintos regímenes del Estado de Bienestar y el de la desmercantilización que opera en las políticas sociales. En relación al primero, la constatación de diferentes regímenes de Estados de Bienestar es realizada por este autor a partir de ciertas dimensiones tales como: las relaciones que se configuran entre Estado, mercado y familia en la satisfacción de las necesidades de reproducción social, las características de la estratificación social y los niveles de desmercantilización en los países seleccionados para su estudio. Así llega a la identificación de tres modelos, agregando que la emergencia de alguno de ellos depende de la interacción entre las variables del poder político y el legado histórico de los países. De este modo, va a indicar la existencia de países, en los cuales, el Estado de Bienestar es "liberal" (liberal residual o de asistencia social) que se caracteriza porque la "ayuda" se otorga a los que se comprueba que no tienen medios, el Estado estimula el mercado y minimiza la desmercantilización, en la que, a la vez se limita el alcance de los derechos sociales. Este modelo construye un orden de estratificación que expresa una relativa igualdad de pobreza para los beneficiarios de la protección social y un bienestar social diferenciado entonces, por el acceso al mercado y un dualismo político de clase entre los dos. Incorpora aquí a Estados Unidos, Canadá y Australia. Un segundo régimen es el conservador (corporativista, seguro social) representado en países como Austria, Francia, Alemania e Italia. La fuerte presencia de la tradición corporativista estatal promueve una cobertura basada en la relación formal del empleo y organizada por programas según riesgo social; las políticas sociales y los derechos reconoce como titular al varón trabajador jefe de hogar y por extensión su familia recibe prestaciones como dependiente de aquél, y no por su carácter de ciudadanos. Mantiene la estratificación, y no valoriza la desmercantilización. Por último, nos encontramos con el régimen "socialdemócrata" (seguridad social o Estado de Bienestar institucional) que promueve la unificación de las diversas políticas, la unificación de las condiciones de adquisiciones de derechos, la cobertura de la población es total en base al status de ciudadanía, cobertura que incorpora todos los riesgos sociales. Dadas estas características, ocurre una disminución de la estratificación social existente, favorece especialmente la desmercantilización, habilita a los ciudadanos a recibir prestaciones sociales que en ciertos momentos de la vida le permiten la sobrevivencia aceptable fuera del mercado de trabajo, son las instituciones estatales las que prestan los 
servicios, promueve el empleo fundamentalmente de mujeres, a pesar de, que la oferta es en los servicios sociales (BRITOS, 2006, 88 y ss).

Reafirmo lo considerado en párrafos anteriores: esta tipología es propia de países europeos, aunque el autor ha tomado además a EEUU, Canadá y Australia, ejemplos sin lugar a dudas de capitalismos "exitosos", al momento de la investigación y por lo menos hasta la primera década del nuevo milenio. No obstante, y siempre desde mi perspectiva, los aportes actúan como parámetro comparativo para nuestra región y es más que conocido el debate sobre sí en nuestros países, pudo en algún momento erigirse un Estado de Bienestar.

Por otra parte, para el tratamiento del concepto de desmercantilización, el autor hace foco en la reproducción social de los trabajadores, expresando que en el paso del pre capitalismo al capitalismo las necesidades humanas y la fuerza de trabajo se convierten en mercancías, dependiendo la sobrevivencia del propio mercado. Al incorporarse los derechos sociales - sigue Esping-Andersen (1993) - se produce una desmercantilización, en tanto el Estado presta un servicio como "asunto de derecho", permitiendo que una persona pueda ganarse la vida sin depender del mercado. No obstante, va a decir también, que no es la mera presencia de un derecho social, sino las reglas correspondientes y las precondiciones las que dictan hasta qué punto los programas del bienestar social ofrecen auténticas alternativas a la dependencia del mercado. Más aún, según sus propias palabras

[...] la desmercantilización no debería confundirse con la erradicación total del trabajo como mercancía; no es un problema de todo o nada. El concepto se refiere más bien al grado en que los individuos o las familias pueden mantener un nivel de vida socialmente aceptable independientemente de su participación en el mercado. (ESPING-ANDERSEN, 1993, p.60).

Así queda claro, por lo menos para algunas concepciones teóricas, que la propia lógica que sostiene el sistema capitalista impide la total desmercantilización de la fuerza de trabajo, en todo caso, el pleno ejercicio, reconocimiento y cumplimiento de los derechos sociales abrirán zonas que se sustraen del juego del mercado.

Antes de introducirme en el tema de las políticas sociales en Argentina, me interesa recuperar algo más que contribuirá en ese desarrollo, y es la consideración de que

[...] las políticas sociales construyen sociedades según principios que las orientan, al generar salario social, operan sobre el momento de la distribución secundaria del ingreso y cumplen una función indirectamente reguladora de las condiciones de venta y uso de la fuerza de trabajo [...] (HINTZE, 2006, p.102). 


\section{Susana Del Valle Cazzaniga}

Claudia Danani se refiere a las políticas sociales

[...] como aquellas específicas intervenciones sociales del Estado que se orientan (en el sentido de que producen y moldean) directamente a las condiciones de vida y de reproducción de la vida de distintos sectores y grupos sociales y que lo hacen operando especialmente en el momento de la distribución secundaria del ingreso [...]. (DANANI, 2004, p.11).

En ese sentido, podemos concluir en que las políticas sociales, siempre al entender, que nos referimos a las sociedades capitalistas a pesar de la hibridización política que para la situación actual región postula Arditi (2009), han cumplido esta misión contradictoria, mientras permite mantener al propio sistema de base, aporta a la sobrevivencia e incluso según los momentos históricos y modelos reconoce derechos fortaleciendo el campo popular. En esta línea, éste es otro aspecto que en realidad, y particularmente para los profesionales de "lo social", se convierte en materia de análisis e interpretación de sus intervenciones, en tanto no es menor reconocer que las políticas sociales modelan estilos de vida y de algún modo construyen sociedades.

Es innegable que las relaciones de fuerza en cada momento histórico y los legados culturales de las regiones y países en relación a los contextos mundiales, producen las condiciones de posibilidad para configurar proyectos sociales que tengan como horizonte de sentido otra sociedad más igualitaria, o que se queden en las simples reformas que sólo aportan a la perpetuación del orden escandalosamente desigual establecido.

\section{Y en Argentina ¿qué?}

En aproximadamente 70 años, al igual que en muchos países de la región, la Argentina pasó vertiginosamente por diferentes matrices políticas y económicas, y en consecuencia, también en lo relativo a las políticas sociales. Sucintamente, podemos hablar de aquellos dispositivos anclados en una sociedad salarial, el violento giro al neoliberalismo, y en estos últimos tiempos una especie de momento de transición, aunque todavía no queda muy claro hacia donde. En lo que sigue, intentaré describir, rápidamente, los dos primeros momentos para luego continuar con los rasgos que adquieren las políticas sociales en la actualidad.

Si bien, los estudiosos del tema no han llegado a un acuerdo acerca de la presencia efectiva en Argentina del Estado de Bienestar, vale reconocer que mi país ha conocido y experimentado un desarrollo más que respetable en torno a las políticas sociales durante la vigencia de la matriz de la sociedad salarial. Más aún, si seguimos la clasificación de Esping-Andersen (1993), podemos claramente reconocer ciertos rasgos de la misma, desde los años 40 
hasta mediados de los 70 del siglo XX, aproximadamente. Evidentemente, las modalidades que adquieren van a presentar su propia particularidad y en este sentido Lo Vuolo y Barbeito expresan que las características propias de la configuración societal de la Argentina define una compleja matriz política en la construcción del sistema de políticas sociales que "[...] derivó en un híbrido donde conviven anárquicamente un discurso universalista, englobador, solidario, con una realidad fragmentaria y particularista" (LO VUOLO; BARBEITO, 1993, p.111). Siguiendo este razonamiento Nora Britos describe el modelo argentino para esa época, tomando la tipificación de Esping Andersen diciendo que se trata de un "mix" entre el régimen conservador o corporativista de protección social al que se asocian rasgos del modelo socialdemócrata, en tanto las políticas de asistencia y promoción social fueron residuales. Según la autora, los aspectos corporativistas se expresaron en la previsión social, las asignaciones familiares y obras sociales que cubren riesgos sociales con la modalidad del seguro por lo que las contribuciones han sido tripartitas (patronales, de los trabajadores y en ocasiones del Estado); la protección entonces se centra en los asalariados formales. La impronta universalista se observa en la política de educación y en menor grado (también mixturada) la de salud, con servicios brindados por el Estado sin restricciones de accesos lo que define el eje en la categoría de ciudadano (BRITOS, 2004). Por último, las políticas de asistencia orientadas a la población que no se incorpora al mercado laboral, son intervenciones en los márgenes (ANDRENACCI, 2002), cuyas prestaciones tanto han sido proporcionadas por el Estado como por organizaciones no gubernamentales; las mismas, además de presentar superposiciones, generan estigmas hacia los grupos sociales a las que se dirigen. En otras palabras, estas políticas se acercan a la tipificación del Estado de Bienestar liberal y más allá de los "retazos" que estructuran este sistema de políticas sociales, no dejan de intentar - con sus particularidades- la reducción de las consecuencias de la desigualdad social. En la misma línea se expresa Pautassi agregando que

En Argentina [...] la dinámica de conformación de los sistemas de políticas sociales estuvo estructurada bajo la lógica de seguros sociales (salud, previsión social, accidentes de trabajo) y estableció como políticas universales a la educación y la salud. (PAUTASSI, 2009, p.187).

En este sentido, la desmercantilización operó en forma dispar. Este modelo funcionó en la Argentina con "sus menos y sus más" hasta mediados de la década de 1970. Con el trasfondo de un proceso subyacente de cambios histórico estructurales en la propia naturaleza del capitalismo (ANDERSON, 1999), la dictadura militar que se instaura en 1976 junto a la 


\section{Susana Del Valle Cazzaniga}

feroz represión, pone las bases para el ingreso de las políticas neoliberales. La apertura democrática condicionada por una fuerte deuda externa y la inestabilidad económica no cambia sustancialmente las transformaciones que se inician durante el gobierno de facto, aunque es en la década de 1990 cuando la materialización de este modelo se expresa con total magnitud. Tal como plantea James Petras

[...] lo que se ha dado en llamar "neoliberalismo' es la restauración política, por la fuerza, de formas anteriores de explotación capitalista (desarraigar las redes económicas locales, minar los mercados nacionales y la formación de los obreros especializados y la clase profesional). (PETRAS, 2007, p.54).

El autor considera a esta restauración como prenacional, mostrando la expansión de los servicios privados de educación y salud y la sustitución de los servicios públicos profesionales por la caridad y el voluntariado.

En el caso que abordo, las propias características del sistema de políticas sociales de esa sociedad salarial a la que mencioné, otorga las condiciones para que el modelo neoliberal produzca en poco tiempo una verdadera debacle social. En efecto, al condensarse la protección social fundamentalmente en los trabajadores formales, las reformas efectuadas en ese núcleo, acompañadas por las privatizaciones de empresas y servicios públicos, la liberación de la economía, las leyes de flexibilización laboral y el debilitamiento de las organizaciones gremiales o su cooptación política, provoca un cambio sustantivo de la sociedad argentina, llegando a índices impensables de desocupación, pobreza e indigencia, con una virtual desaparición de lo que otrora fuera el carácter distintivo de mi país: los sectores medios.

Nora Britos sintetiza los efectos de la aplicación de estas políticas de esta manera:

[...] a) ampliación de la participación del mercado en la oferta de bienestar social, especialmente en las políticas con base contributiva que cuentan con financiamiento y funciones de producción que las tornan 'oportunidades de negocios’; b) definición restrictiva del concepto de bien público; c) aumento de las condiciones de acceso a prestaciones de las políticas contributivas estrictamente basadas en la trayectoria laboral; d) deterioro por desfinanciamiento de las políticas universalistas (educación y salud pública); e) promoción y revalorización de la vigencia de políticas de asistencia basadas en comprobación de medios para asignar beneficios; f) impulso sostenido a los programas de asistencia basados en las contraprestaciones laborales como requisito para obtener subsidios [...]. (BRITOS, 2004, p.7).

Así, en relación a las políticas sociales, encontraremos grupos que obtienen protección social en el mercado: jubilaciones, obras sociales, escuelas 
privadas, entre otras. Son los sectores que mantienen una relación laboral formal y particularmente, aquellos calificados y que trabajan, generalmente, en empresas multinacionales. El resto, trabajadores de baja calificación o del sector servicios y el creciente número de desocupados e inempleables, debe recurrir a los servicios públicos altamente deteriorados y/o a los programas asistenciales focalizados.

La desigualdad que se instala es apabullante, dejando como marca, por lo menos, dos argentinas, lo que trastoca fuertemente la subjetividad dando lugar a nuevas formas culturales. $\mathrm{Y}$ en esto es que quiero detenerme: junto al proceso de degradación material se va dando un cambio de sentido en lo que refiere a valores: el individualismo, la competencia feroz entre pares, el clientelismo, la violencia generalizada, la discriminación que raya en la xenofobia en ciertos casos y hasta la delación atraviesan a la sociedad en su conjunto. Las políticas focalizadas contribuyen a estos "moldeados" como planteara en párrafos anteriores, acentuando en los sectores pobres la estigmatización, pero también internamente se observa el reemplazo de los lazos, en otros momentos solidarios, por relaciones coyunturales sujeta a intereses individuales o grupales. En esta dimensión el neoliberalismo ha ganado una batalla.

\section{Después del 2001}

En Argentina “el 2001” se ha convertido en emblemático, constituyéndose como acontecimiento, en tanto es la clara (y dolorosa) constatación de la inviabilidad del modelo hegemónico. La profunda crisis, el estallido social y las demandas de una sociedad movilizada desembocan en un proceso "espinoso" tendiente a la estabilización política y económica, esta vez zanjada sin la participación de las fuerzas armadas.

A partir del 2003, momento en que asume la presidencia Néstor Kirchner se va dando una paulatina y siempre relativa estabilidad, que junto al crecimiento económico, el mantenimiento del tipo de cambio una vez salidos de la convertibilidad y sin mudanzas significativas del modelo económico (que es la lógica extractiva de recursos naturales a la que se anexa su exportación vinculada al valor agregado) repone al Estado como agente activo de la asignación de recursos. El actual gobierno intenta recuperar y potenciar las capacidades estatales sin restringir el funcionamiento del mercado, buscando en todo caso una complementariedad entre ambos.

Los discursos oficiales remarcan como principio rector de su política "el crecimiento con inclusión” y salta a la vista ciertas medidas en las que se muestra, que la cuestión social se encuentra en la agenda pública. 


\section{Susana Del Valle Cazzaniga}

Entre ellas se puede nombrar: el aumento importante de la inversión estatal en el área, las políticas en materia de previsión social (la estatización de la seguridad social, el Plan de inclusión previsional ${ }^{3}$, la mejora en los montos jubilatorios: aumento del haber mínimo y una actualización bianual de los haberes jubilatorios nacionales en base a una ecuación polinómica ${ }^{4}$. Por otra parte, la estatización de la AFJP (Jubilaciones privadas) significó el ingreso a las arcas de un monto de dinero importante que es redireccionado hacia el sector productivo interno. Otro de los ejes tomados con preferencia se encuentra en la cuestión del empleo que va desde políticas reguladoras del empleo formal: aumento del salario mínimo vital y móvil, restablecimiento de las negociaciones colectivas de trabajo; ante la crisis internacional del año 2008 se lanzó el Programa de recuperación productiva con el objetivo de sostener el empleo genuino, así se apoyó a empresas en crisis brindando una suma mensual por el plazo de 12 meses destinado a completar el salario de la categoría laboral correspondiente.

Respecto de las políticas sociales promocionales y asistenciales desde lo que va del 2003, encontramos diferentes medidas. En un principio más ligadas al formato "enlatado" propio de las recetas de los organismos internacionales de financiamiento, sobre las que se fueron ensayando modificaciones. Hoy y según el Ministerio de Desarrollo Social de la Nación existen dos líneas: Argentina Trabaja y Familia Argentina, al interior de las cuales existen diferentes líneas.

\section{Argentina trabaja}

\section{Líneas:}

\section{Ingreso Social con Trabajo}

Programa destinado a mejorar la calidad de vida de las familias de los barrios más vulnerables a través de la generación de puestos de trabajo, capacitación y promoción de la organización cooperativa para obras de infraestructura local.

\footnotetext{
3 Para todos aquellos ciudadanos que teniendo las edades establecidas por ley para obtener la jubilación - 60 años para las mujeres y 65 para los varones - y no cuenten con los aportes correspondientes. Estas personas acceden a la prestación y sobre el monto se descuenta mensualmente un porcentaje para contribuir con el sistema. El límite se puso hasta los nacidos en el año 1948.

4 No se repuso el 82\% móvil como históricamente estaba establecido y fuera retirado en los 1994 por el entonces ministro de Economía Domingo Caballo durante el gobierno de Saúl Menem a pesar de las sentencias de la Corte Suprema de Justicia al respecto.

5 Se describen en forma general las diferentes líneas, para una mayor profundización consultar en <http://www.desarrollosocial.gov.ar>.
} 


\section{Proyectos socio productivos "Manos a la obra"}

Fomento del autoempleo (proyectos productivos personales o asociativos). Se financia herramientas de trabajo y asistencia técnica.

\section{Marca colectiva}

Fortalecimiento de la producción y comercialización de emprendimientos garantizando la calidad. Se intenta fomentar el comercio justo y el consumo responsable.

\section{Microcréditos}

Financia y promueve emprendimientos productivos, comerciales o de servicios. Se otorgan préstamos a bajo interés o sin intereses.

\section{Monotributo social}

Categoría tributaria para la incorporación a la economía formal de personas en situación de vulnerabilidad. Mediante la inscripción, las personas gozan de las prestaciones de Obra Social y realizan aportes jubilatorios.

\section{Familia Argentina}

\section{Líneas}

Niñez

Desde la sanción en el año 2005 de la Ley 26061 de Protección Integral de los Derechos del Niño, Niña y Adolescentes se crea la Secretaría Nacional de la Niñez Adolescencia y Familia (SENAF) y el Consejo Federal de Niñez, Adolescencia y Familia. Estas instituciones planifican las políticas públicas destinadas a esta población. El objetivo es el fortalecimiento de la familia como base para un desarrollo humano sustentable.

\section{Juventud}

En esta línea, las políticas públicas se conciben impulsadas desde el territorio con y desde las juventudes, delineándose varios objetivos que dan lugar a diversas actividades y programas. "Promover la movilización y participación solidaria": Jornadas solidarias y capacitaciones; "generar procesos y espacios de formación política": programas Pensar Argentina, Mirar Latinoamérica, Argentina soberana y popular, Jóvenes cooperativistas Argentina Trabaja, Centros de Estudiantes, Democracia participativa y políticas públicas, Talleres de comunicación; “implementar estrategias y acciones de articulación conjunta con 
diferentes organizaciones". Estas acciones se llevan adelante por la Dirección Nacional de juventud y el Consejo Federal de Juventud.

\section{Adultos mayores}

Los distintos programas se impulsan desde la Dirección Nacional de Políticas para Adultos Mayores dependiente de la Secretaría de Niñez, Adolescente y Familia. Entre varias acciones y programa se destacan la capacitación para cuidados domiciliarios y el programa. La experiencia cuenta que intenta el encuentro de generaciones mediante la transferencia de saberes. Además se desarrolla la Carrera de Especialización en Gerontología comunitaria e institucional.

\section{Pensiones no contributivas}

A través de la Comisión Nacional de pensiones y en coordinación con los Centros de Atención Local, Centros de referencia y el Tren de Desarrollo social y sanitario se tramitan pensiones a la vejez, por invalidez, madres de más de 7 hijos; pensiones graciables, por leyes especiales.

\section{Comunidad}

Se promueve el trabajo conjunta con todas las familias mediantes políticas, cuyos ejes son: inclusión, participación y organización. Estos objetivos se materializan a partir de la creación de Centro integradores comunitarios (espacios públicos donde se articulan las instancias nacionales, provinciales, municipales, organizaciones sociales y políticas. En estos centros se coordinan políticas de desarrollo social y atención primaria de la salud, actividades culturales, recreativas y de educación popular); Plan Ahí (mediante la coordinación de las instancias nacionales y provinciales en pequeños pueblos, parajes, barrios aislados social o geográficamente); Tren de desarrollo social y sanitario (un tren se desplaza por los parajes, cuyos habitantes tienen problemas para acceder a distintos servicios. Se realiza atención de la salud y asesoramiento en políticas sociales); Promotores comunitarios; Capacitación Popular.

\section{Seguridad alimentaria}

El Plan nacional de seguridad alimentaria (Ley 25724/03) posibilita el acceso de la población a una alimentación adecuada, contemplando lo dispuesto por la F.A.O: la disponibilidad de alimentos, su acceso, buena selección, correcta elaboración, manipulación y conservación, adecuada distribución dentro del grupo familiar y un buen aprovechamiento para el organismo. Se lo implementa mediante los siguientes programas: 
Familias y nutrición; Abordaje comunitario; Pro - huerta; Educación alimentaria y nutricional.

\section{Deporte y recreación}

Considerada a la actividad física y a la recreación como derechos, se implementan programas desde la Secretaría de Deporte de la Nación: Juegos nacionales Evita; Nuestro club; Argentina nuestra cancha; Deporte federado y de representación nacional.

En términos generales y aunque en los fundamentos de cada programa, encontramos enunciaciones tales como "enfoque de derechos"; "ciudadanos y no beneficiarios"; "avances sobre el clientelismo"; "integralidad territorial"; podemos realizar algunas consideraciones al respecto:

a. Estos programas nacionales se desarrollan en las provincias y ciudades luego de la firma de un convenio entre la instancia nacional y las provinciales. Así encontramos que por diversas razones, en general por cuestiones políticas partidarias, algunos convenios no se celebran y por lo tanto, los mismos no llegan a todo el país.

b. Su implementación queda en manos de diferentes actores sociales, que en general mantienen la lógica asistencialista, paternalista y clientelar, por lo tanto, en el territorio se desdibujan las posibilidades de que los propios vecinos se conviertan en sujetos políticos de estos programas. De esta manera, los fundamentos y principios que aparecen en su formulación quedan más declamativos que puestos en acto.

c. Existen superposiciones jurisdiccionales entre nación, provincia y municipio, y por otro lado, en el mismo nivel nacional existen programas sociales que dependen de diferentes ministerios. A pesar de la existencia de una mesa de coordinación de políticas sociales, en la cual "se sientan" los representantes de los distintos ministerios, en la práctica encontramos más serias dificultades de coordinación.

Como conclusión provisoria, podemos considerar que más allá de lo discursivo y por una multiplicidad de aspectos, el despliegue de estos programas no logran romper totalmente con la lógica tutelar, entendiendo que existen honrosas excepciones. De esta manera se puede hablar de continuidades, entendiendo las contradicciones existentes. 


\section{La asignación universal por hijo: ¿hace diferencia?}

Desde octubre de 2009 se lanza la Asignación Universal por Hijo $(\mathrm{AUH})$ mediante un decreto modificatorio de otro que regula las asignaciones familiares para los trabajadores formales. Esta prestación cubre a los trabajadores informales, desocupados y personal de servicio doméstico, que tengan hijos menores de 18 años y se abona hasta cinco hijos, un $80 \%$ directamente y un $20 \%$ se deposita en una cuenta bancaria, y puede ser retirado una vez que se haya acreditado la concurrencia a la escuela y el cumplimiento de los controles sanitarios. Está a cargo del ANSES (Administración Nacional de Seguridad Social).

El fundamento central de la AUH lo otorga la ley 26061 (de Protección integral de los Derechos de la Niña, Niño y Adolescentes); a la vez rompe con la perspectiva corporativista (beneficios ligados a la relación laboral formal) al extender el reconocimiento de derechos a otros sujetos; la ANSES como encargada de las tramitaciones correspondientes iguala las prestaciones para los que están incluidos en el mercado laboral y los que no, sustrayendo a este último sector social de las intervenciones estigmatizadoras (por lo menos en esto); toma la universalización como fin y la focalización como instrumento proponiendo un esquema de universalismo a través de "la selectividad".

El presupuesto para la AUH alcanza al 1\% del PBI. Esta asignación sienta un piso desde el cual avanzar hacia políticas más cualitativas y promocionales de garantías de derechos y a favor de la concreción de los derechos de la infancia (MAZZOLA, 2010).

Esta política, que en los últimos días se ha extendido para las embarazadas a partir del tercer mes de gestación, por las características generales enunciadas, emerge como ruptura de los programas sociales más asociados a la lógica neoliberal. No obstante, y en coincidencia con algunos autores, se deberían debatir algunos puntos para que realmente se convierta en una política de estado centrada en los derechos.

En primer lugar, sostengo que debería estar respaldado por una ley lo que significa por una parte, una relativa garantía de continuidad, y por otro lado, se llevaría a debate público un tema que merece ser considerado por las mayorías. Allí mismo se podría establecer las fuentes de financiamiento y la movilidad de los montos a fin de que no caiga en discreciones del poder ejecutivo.

Otro tema central es la discusión sobre la transferencia condicionada (debate que excede en creces a la $\mathrm{AUH}$ ) ya que, lo que se solicita es que se cumpla con los controles de salud y escolaridad. Si consideramos que salud y educación son derechos, por definición éstos no pueden condicionarse, en todo caso y siguiendo en este punto a Roxana Mazzola (2010), se podría 
incorporar la noción de corresponsabilidad: el estado se compromete a las prestaciones como responsable de brindar los servicios de salud y educación, y los padres responden en consecuencia, velando también por los derechos de los niños, niñas y adolescentes. La AUH modifica el panorama de las políticas sociales, pero no resuelve el problema de la pobreza. Cambia el sujeto, ahora es la familia, lo que también debe tomarse con la complejidad que esto merece: es altamente significativo que se cambie la lógica de los programas por segmentos etarios o por riesgo, pero es interesante repensar la cuestión de la familia para no volver a propuestas conservadoras.

\section{Lo que el viento se llevó, lo que quedó, lo deseable, lo por venir}

Consecuente con esta "política híbrida" a decir de Arditi (2009), pero como hemos visto una característica que acompaña el propio surgimiento del sistema de políticas sociales en Argentina, observamos que tal impronta se mantiene con los "aggiornamientos del caso". De esta manera se puede hablar de continuidades y rupturas, de allí que creo que debemos ser cautos a la hora de expresarnos por las características de las políticas sociales. En efecto, en mi país encontramos aquéllos que abogan por el worfare de raigambre liberal (focalización y condicionalidad, o en otras palabras "ganarás tu bienestar con tu propio esfuerzo"), hasta los que batallan por la universalidad plena. Frente a estos nuevos escenarios capitalistas, y particularmente ante la inmensa desigualdad que padecemos (no sólo Argentina, sino toda la región) se hace necesario revisar la cuestión de las políticas sociales en por lo menos algunos aspectos:

- Todo sistema de políticas sociales depende de los proyectos políticos y de la pugna entre ellos. En ese sentido, las políticas sociales son tributarias de las concepciones ideológicas, políticas, teóricas y éticas que circulan en las sociedades y particularmente de las relaciones de fuerza de las distintas facciones ideológicas políticas en lucha.

- Si acordamos en que las políticas sociales son mecanismos de redistribución ajustado a los derechos humanos y entre ellos los sociales, obviamente, tenemos que discutir hoy la cuestión de la universalidad. Está más de manifiesto que la focalización sólo estigmatiza y fragmenta, desconociendo la vida cotidiana de los sujetos. La pregunta que surge es cómo dar cuenta de la universalidad en una coyuntura de fuerte desigualdad, en tanto esa misma universalidad siempre va a ser tributaria de los principios distributivos que la sociedad está en condiciones de consensuar. Dicho en otros términos, 
la posibilidad de la universalidad plena corre paralela con aquellas relaciones de fuerza a la que me referí en párrafos anteriores, una lucha decididamente política que se dirime en el seno de la sociedad. Mientras estas cuestiones se dirimen y como una salida absolutamente provisoria y coyuntural, es que propongo retomar el concepto de selectividad y analizar caso por caso (política por política), las condiciones para reconocer cuando es posible la universalización y cuando es necesario (provisoriamente) sostener la selectividad.

- Otro concepto necesario de discutir es el de condicionalidad. Nuevamente si nos referimos a los derechos, los mismos no pueden estar condicionados; ahora bien, ante la devastación cultural sufrida, es necesario incidir en la construcción de sujetos plenos, activos políticamente y en ese sentido la responsabilidad es un valor imprescindible, en tanto y en cuanto el Estado cumpla con "su" responsabilidad al respecto, esto es, ofrecer los bienes y servicios correspondientes en tiempo y forma. Se trata de correr del plano discursivo y práctico, la noción de condicionalidad para incorporar fuertemente el principio de co responsabilidad: así como sujetos de las políticas sociales tenemos responsabilidades que asumir, el Estado como garante es responsable de "proveer".

En síntesis, se trata de un momento particular en que se yuxtaponen concepciones, idearios y proyectos políticos diversos. De cómo se construirá una contra hegemonía dependerá ciertamente las características que tendrán las políticas sociales, y en este sentido, es más que interesante comprender las condiciones de posibilidad que se abren (o no) en este escenario, a decir de Arditi, de hibridización política.

\section{Bibliografía}

ANDRENACCI, Luciano (Org.). Cuestión social y política social en el Gran Buenos Aires: Ediciones Al Margen, 2002.

ARDITI, Benjamín. El giro a la izquierda en América Latina:¿una política pos liberal? Revista Ciencias Sociales Unisinos, v.45, n.3, 2009. Universidade do Vale do Rio dos Sinos, Brasil.

BRITOS, Nora. Astucias de la razón neoconservadora: del silencioso desplazamiento de los derechos a las obligaciones en el campo de la asistencia social. Revista Topos \& Tropos, n.1, 2004. 
DANANI, Claudia. El alfiler en la silla: sentidos, proyectos y alternativas en el debate de las políticas sociales y la economía social. Em: DANANI, Cláudia (Comp.). Políticas social y Economía sócial: debates fundamentales, Buenos Aires: UNGSOSDE-Altamira, 2004.

DÁVALOS, Pablo. El centro del problema no es el neoliberalismo, es el capitalismo. Entrevista realizada por Verónica Gago y Diego Sztulwark. Em: Diario Página 12, Buenos Aires, 11 de abril de 2011.

ESPING ANDERSEN, Gosta. Los tres mundos del estado de bienestar. Edicions Alfons El Magnanim Institució Valenciana i Investigació. Generalitat valenciana. Valencia: Diputació provincial de Valencia, 1993.

GRUENBERG, Christian; PEREYRA IRAOLA, Victoria. El clientelismo en la gestión de programas sociales contra la pobreza. CIPPEC Documento de Políticas Públicas. Análisis, n.60, Buenos Aires, 2009.

HINTZE, Susana. Exclusión, derechos y políticas sociales: la promoción de formas asociativas y trabajo autogestivo en la Argentina. Revista FERMENTUM, Año 16, n. $45,2006$.

LO VUOLO, Rubén; BARBEITO, Alberto. La nueva oscuridad de la política social. Del Estado Populista al Neoconservador. Ciepp - Miño y Dávila Editores, Buenos Aires, 1993.

MOCCA, Edgardo. Las dos almas de la izquierda reformista argentina. Revista Nueva Sociedad, n.217, Buenos Aires: Fundación Friedrich Ebert, 2008.

PAUTASSI, Laura C. El bicentenario de la política social: ¿Nuevos modelos o viejas estrategias? Postdata, Ciudad Autónoma de Buenos Aires, v.14, n.1, jul. 2009. Disponible en: $<$ http://www.scielo.org.ar/scielo.php?script=sci_arttext\&pid $=$ S185196012009000100004\&Ing=es\&nrm=iso >. Fecha de acceso: 5 mayo 2010.

; ZIBECCHI, Carla. La provisión de cuidado y la superación de la pobreza infantil. Programa de transferencias condicionadas en la Argentina y el papel de las organizaciones sociales y comunitárias. Santiago de Chile: CEPAL/ UNICEF, 2010. Serie Políticas Sociales, n. 159.

PEREZ MUÑOZ, Cristian. Por qué los gobiernos de izquierda no apuestan a políticas universales de empleo e ingresos? Una revisión normativa y empírica de las experiencias de Argentina, Chile, Brasil y Uruguay. Informe final del concurso: transformaciones en el mundo del trabajo: efectos socioeconómicos y culturales en América Latina y el Caribe. Programa Regional de Becas CLACSO, 2006. Disponible en: <http://bibliotecavirtual.clacso.org.ar/ar/libros/becas/2005/2005/trabjov/ perez.pdf $>$. Fecha de acceso: 02 de abril de 2011.

PETRAS, James. Repensar el desarrollo de Amperica Latina y el Caribe para el siglo XXI. Revista del Instituto Argentino para el Desarrollo Argentino. IAD, Buenos Aires, 2007. 
RANCIERE, Jaques. El desacuerdo: política y filosofía. Buenos Aires: Nueva Visión, 1996.

SADER, Emir; GENTILI, Pablo. (Comp.). La trama del neoliberalismo: mercado, crisis y exclusión social. Buenos Aires: Eudeba, 1999. 